\title{
Supply Chain Sustainability Assessment: the Case of the Automotive Industry
}

\author{
Miguel M. Barros ${ }^{1}$ and Susana G. Azevedo ${ }^{2, *}$ \\ ${ }^{1}$ Department of Electromechanical Engineering, University of Beira Interior, Portugal \\ ${ }^{2}$ CEFAGE-UBI, UNIDEMI, Department of business and Economic, University of Beira Interior, Portugal \\ *Corresponding author
}

\begin{abstract}
The objective of this paper is to propose a framework to assess and monitor the level of sustainability at the automotive supply chain, followed by its validation with a case study considering several companies from United Kingdom (UK).
\end{abstract} chain

Keywords-sustainability; framework; composite index; supply

\section{INTRODUCTION}

There is a lack of methods for assessing the sustainability of supply chains in an integrated way and considering at the same time the economic, social and environmental dimension. Based on the work of Salvado, Azevedo, Matias and Ferreira [1], this paper proposes a way of assessing and monitoring the overall sustainability behaviour of the automotive supply chain. The framework consists of a set of six steps and uses the Simple Additive Weighting (SAW) method to aggregate economic, environmental and social indicators into a unique value. The proposed framework represents a contribution in the area of index construction and a valuable component of organizational management systems and monitoring programs, serving as a benchmarking tool for managers to evaluate the sustainability behavior of their own supply chain and compare it with other supply chains, in order to improve the dimension of sustainability in which they perform worst.

This paper is organized as follows. First, a succinct theoretical background on the sustainability is present. Then, the proposed framework is described, illustrating the steps associated to the construction of the index. The following sections covers the case study before the drawn of conclusions.

\section{THEORETICAL BACKGROUND}

A more sustainable form of business requires that the environmental, economic and social issues must be integrated into supply chain management [2-3]. So, an integrated approach is necessary when considering the supply chain perspective [4]. Despite several sustainability measurement initiatives, only few have integrated simultaneously the environmental, economic and social dimensions [5-7].

A composite index can be applied for measuring supply chain sustainability, although using too many indicators complicates the sustainability assessment process [8]. A proper approach to management decisions, such as with sustainable supply chains, implies involving various participants and perspectives; therefore it is a challenge to reduce all dimensions to a single measure. To overcome this difficulty, it can be used multi-criteria evaluation methodologies.

The framework proposed in this paper extends also the hierarchical approach suggested by Azevedo, Govidan, Carvalho and Cruz-Machado [9-10], in which an ecologicalresilience index and an agile-lean index are developed. The hierarchical approach followed in this framework considers that the supply chain is composed of a set of $n$ companies, each one with different degrees of economic, social and environmental performance and the overall supply chain sustainability will be affected by the aggregation of individual companies' behaviours that are previously computed.

\section{PROPOSED FRAMEWORK}

Firstly, the company sustainability index ( $\left.I_{C_{-} S U S T}\right)$ is computed. To this end, three sub-indices $\left(I_{S_{f}}\right)$ are suggested based on the approach proposed by Krajnc and Glavič [11] and Zhou, Ang and Zhou [12], considering: $\mathrm{j}=1$ economic dimension; $\mathrm{j}=2$ environmental dimension; and $\mathrm{j}=3$ social dimension. Each sub-index is computed using a set of indicators. After that, the supply chain sustainability index $\left.\left(E_{E S S N S F}\right)^{2 v e r a I}\right)$ is computed by aggregating the sustainability sub-indices. Figure 1 illustrates the framework:

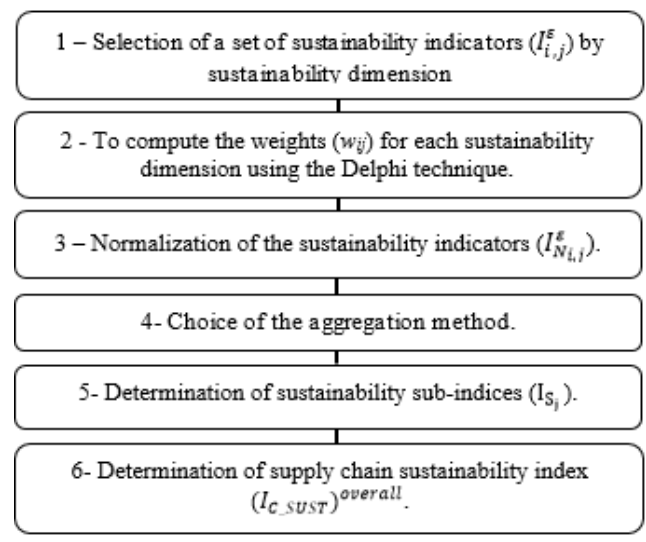

FIGURE I. FRAMEWORK FOR THE ASSESSEMENT OF THE SUSTAINABILITY INDEX, ADAPTED FROM [1].

\section{A. Methodology and Data Collection}

This study intends to test the proposed sustainability index adapted from the methodology suggested by Salvado, Azevedo, 
Matias and Ferreira [1] in the automotive industry. To attain this objective a qualitative methodology was used to identify a set of economic, social and environment indicators of 25 automotive industries at UK (based in 25 sustainability reports from 1999 to 2014, gathered in a web-based search), in order to compute and test the sustainability index of the UK' automotive supply chain.

\section{APPLICATION OF THE SUGGESTED FRAMEWORK - CASE STUDY}

In this section, the proposed framework is tested, using the sample collected.

\section{A. $1^{\text {st }}$ step - Selection of Sustainability Indicators}

The indicators in Table I were chosen because they were the only set that is present in all the sustainability reports of the 25 research companies of the UK automotive supply chain and are present also the Global Reporting Initiative (GRI).

TABLE I. SUSTAINABILITY INDICATORS

\begin{tabular}{|c|c|c|c|}
\hline & Indicator & $\begin{array}{c}\text { Unit of } \\
\text { measurement }\end{array}$ & Type of indicator* \\
\hline \multirow{3}{*}{ 导 } & $\begin{array}{l}\text { - Automotive } \\
\text { manufacturing } \\
\text { sector turnover }\end{array}$ & $£$ billion & $\begin{array}{c}\mathrm{I}_{1,1}^{+}-\text {The larger the } \\
\text { better }(+)\end{array}$ \\
\hline & $\begin{array}{l}\text { - Automotive sector } \\
\text { value added }\end{array}$ & $£$ billion & $\begin{array}{c}\mathrm{I}_{2,1}{ }^{+} \text {- The larger the } \\
\text { better }(+)\end{array}$ \\
\hline & $\begin{array}{l}\text { - Total number of } \\
\text { new cars produced }\end{array}$ & Quantity & $\begin{array}{c}\mathrm{I}_{3,1}{ }^{+} \text {- The larger the } \\
\text { better }(+)\end{array}$ \\
\hline \multirow{5}{*}{ 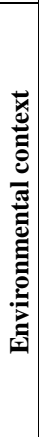 } & $\begin{array}{l}\text { - Total combined } \\
\text { energy use }\end{array}$ & GWh & $\begin{array}{l}\mathrm{I}_{1,2}^{-}-\text {The smaller } \\
\text { the better }(-)\end{array}$ \\
\hline & $\begin{array}{l}\text { - Water use per } \\
\text { vehicle produced }\end{array}$ & $\mathrm{m} 3 /$ unit & $\begin{array}{c}\mathrm{I}_{2,2^{-}}-\text {The smaller } \\
\text { the better }(-)\end{array}$ \\
\hline & $\begin{array}{l}\text { - } \mathrm{CO} 2 \text { equivalent per } \\
\text { vehicle produced }\end{array}$ & tonnes & $\begin{array}{c}\mathrm{I}_{3,2}{ }^{-}-\text {The smaller } \\
\text { the better }(-)\end{array}$ \\
\hline & $\begin{array}{l}\text { - Waste to landfill } \\
\text { per vehicle } \\
\text { produced } \\
\end{array}$ & kg/unit & $\begin{array}{c}\mathrm{I}_{4,2}^{-}-\text {The smaller } \\
\text { the better }(-)\end{array}$ \\
\hline & $\begin{array}{l}\text { - Site waste for } \\
\text { recycling per } \\
\text { vehicle produced }\end{array}$ & $\mathrm{kg}$ /unit & $\begin{array}{c}\mathrm{I}_{5,2}{ }^{+}-\text {The larger the } \\
\text { better }(+)\end{array}$ \\
\hline \multirow{2}{*}{. } & $\begin{array}{l}\text { - Number of lost- } \\
\text { time incidents }\end{array}$ & Quantity & $\begin{array}{c}\mathrm{I}_{1,3^{-}}-\text {The smaller } \\
\text { the better }(-)\end{array}$ \\
\hline & $\begin{array}{l}\text { - Number of training } \\
\text { days per employee }\end{array}$ & Quantity & $\begin{array}{l}\mathrm{I}_{2,3}^{+}-\text {The larger the } \\
\text { better }(+)\end{array}$ \\
\hline
\end{tabular}

\section{B. $\quad 2^{\text {nd }}$ step - Computing Weights Using the Delphi Technique}

The success of the Delphi method depends mainly on the careful selection of the panel members. A purposive approach was adopted to select this group of experts [13], using the following two criteria in order to identify eligible participants for this part of the study: i) having current/recent involvement in automotive industry research topics; ii) having a sound knowledge and understanding on sustainability. In order to obtain the most valuable opinions, only academics who met the two selection criteria were considered. As regards the selection of professionals from the industry the main criteria used was working in a company belonging to the automotive supply chain.

A total of 12 panel members were invited to participate in this study. Virtual interviews were launched with academics and professionals, to assess the importance of the economic, social and environmental behavior of the companies to the sustainability of the automotive supply chain. The first round of Delphi questionnaire was sent to the group of panel members by e-mail at the end of January 2016. The results of this round were consolidated and presented to the panel members. Then they were requested to reconsider whether they would like to change any of their original choices in the light of the consolidated results from the first round. All the twelve questionnaires were completed at the end February 2016.

\section{C. $3^{\text {rd }}$ step - Normalization of the Sustainability Indicators}

Since the economic, social and environmental indicators are expressed in different units, normalization is necessary. That step was done by using the Minimum-Maximum method, allowing the selected indicators to be integrated into an aggregated index for sustainability assessment. The following equations were used to compute the weighting for the three sustainability dimensions (Table II):

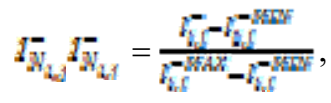

where:

$\Gamma_{N_{i S}}$ - is the normalized indicator $i$ from the dimension of sustainability $j$ with negative impact on sustainability.

$I_{i}$ - is the indicator $i$ from the dimension of sustainability $j$ with negative impact on sustainability.

$F_{t}^{-W N}$ - represents the lowest value of indicator $i$ from the dimension of sustainability $j$ with negative impact on sustainability.

$F_{t}^{-M A X}$ - represents the highest value of indicator $i$ from the dimension of sustainability $j$ with negative impact on sustainability.

The order of importance of the sustainability dimensions obtained from the academics/professionals perception, after the two rounds, is the following one: the most important is environment sustainability. As can be seen from the Kendall's coefficient of concordance the consistency of the academics/professionals rankings was lightly improved after the Round 2.

Analyzing the results of Table II, it can be seen that to the environmental dimension $\left(\mathrm{I}_{1}\right)$ is given greatest importance with a weight of $46 \%$, while the social dimension was considered least important at $23 \%$. 
TABLE II. RESULTS OF ROUND 1 AND ROUND 2 OF DELPHI METHOD FOR THE MEASURING OF SUSTAINABILITY DIMENSIONS' IMPORTANCE

\begin{tabular}{|c|c|c|c|c|c|c|}
\hline \multirow[b]{2}{*}{$\begin{array}{l}\text { Sust. } \\
\text { dimensions }\end{array}$} & \multicolumn{3}{|c|}{ First round } & \multicolumn{3}{|c|}{ Second Round } \\
\hline & 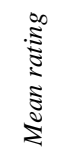 & $\underset{\Xi}{\stackrel{\Xi}{\Xi}}$ & 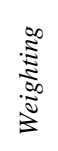 & 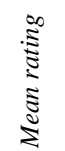 & $\underset{\mathfrak{\Xi}}{\tilde{E}}$ & $\begin{array}{l}\frac{0}{5} \\
\frac{\pi}{2} \\
3 \\
3\end{array}$ \\
\hline Social & 2,36 & 3 & 0,25 & 2,42 & 3 & 0,23 \\
\hline Economic & 3,15 & 2 & 0,34 & 3,41 & 2 & 0,32 \\
\hline Environment & 3,89 & 1 & 0,41 & 4,91 & 1 & 0,46 \\
\hline Number (n) & \multicolumn{3}{|c|}{12} & \multicolumn{3}{|c|}{12} \\
\hline $\begin{array}{l}\text { Kendall's } \\
\text { Coefficient of } \\
\text { concordance }(\mathrm{W})\end{array}$ & \multicolumn{3}{|c|}{0.623} & \multicolumn{3}{|c|}{0.669} \\
\hline $\begin{array}{ll}\text { Level } & \text { of } \\
\text { significance } & \end{array}$ & \multicolumn{3}{|c|}{0.025} & \multicolumn{3}{|c|}{0.006} \\
\hline \multicolumn{7}{|c|}{$\begin{aligned} \text { Note: For "Mean rating" } & 1 \text { nothing important and } 5=\text { extremely } \\
& \text { important }\end{aligned}$} \\
\hline
\end{tabular}

\section{D. $4^{\text {th }}$ step - Choice of the Aggregation Method}

The aggregation method used in this study is the Simple Additive Weighting method (SAW). The SAW method requires that the social, economic and environmental variables are preferentially independent, which may be difficult to satisfy. However, even if the assumption does not hold, the SAW method would also yield an extremely close approximation to the ideal value function [14]. Despite this limitation, the SAW method has been widely used in practice due to its transparency and ease of understanding by non-experts [15].

\section{E. $\quad 5^{\text {th }}$ step - Computing the Sustainability sub-Indices by Sustainability Dimension}

At this phase the weights are determined and indicators normalized, which makes possible that the sustainability subindices could be computed by economic, social and environmental dimensions and using the following equation:

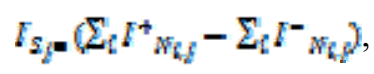

where:

$I_{s_{j}} \quad$ - it is the sustainability sub-index for the sustainability dimension $j \quad(j=1$ economic dimension; $j=2$ environment dimension; $j=3$ social dimension).

$I_{N_{Z \zeta}}^{+}$- represents the normalized indicator I, with a positive impact on sustainability for the sustainability dimension $j$.

$I_{\bar{R} \delta}$ - represents the normalized indicator $I$, with a negative impact for the sustainability dimension $j$.

As regards the economic sub-index of sustainability as all the indicators chosen to translate the economic dimension of sustainability have a positive impact on the sustainability the factor $\Sigma_{1} I^{-} \mathbb{\Delta}_{4}$ it is not considered in the former equation.

\section{F. $6^{\text {th }}$ step - Computing the Supply Chain sustainability Index}

The sustainability index for the UK automotive supply chain was obtained by aggregating the weighted sub-indices into a unique value using the following equation:

$$
I_{S j, S U S T}=\Sigma_{j} I_{S S_{j}} w_{j},
$$

where:

$I_{s_{j}}$ - represents the sustainability sub-index, considering the sustainability dimension $j$ ( $j=1$ economic dimension; $j=2$ environment dimension; $\mathrm{j}=3$ social dimension).

wj - represents the weight associated to the sustainability dimension $\mathrm{j}, \sum w_{j}=1$ and $w \mathrm{w} \geq 0$.

As can be seen in Figure 2, the sustainability of the UK automotive supply chain is getting better over time. During the first years of this century the automotive industry was not so concerned with sustainability, mainly with environmental issues. From 2004 a more sustainable behavior was adopted which reflects a grown in the SC sustainability index. The year of 2009 was not so good in terms of sustainability representing a decrease in the sustainability index.

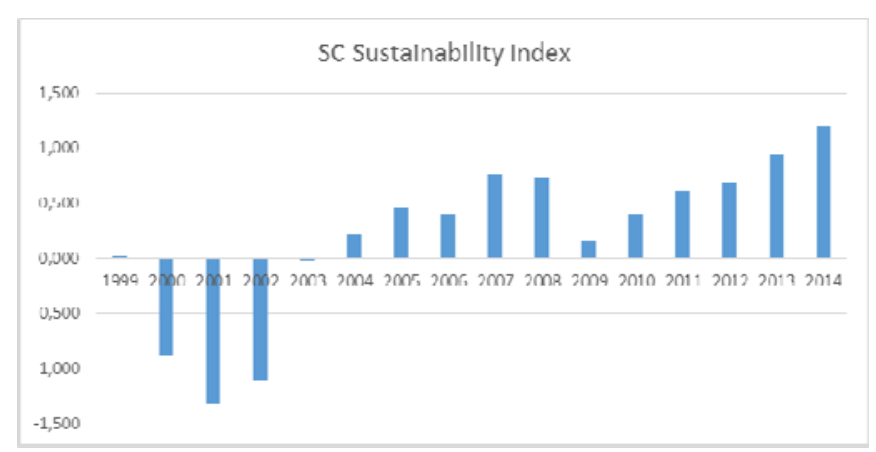

FIGURE II. EVOLUTION OF THE SUPPLY CHAIN

Figure 3 illustrates the behavior of UK automotive SC in terms of the overall sustainability and social, economic and environmental sustainability. The environmental dimension of sustainability is the one that presents the worst values, being negative during the period between 1999 and 2004. After that the concerns with the environment grown contributing for increasing this sustainability sub-index. The economic dimension of sustainability has during the focused time horizon a positive behavior being the higher during almost all the time except in 2009 . The social dimension of sustainability presents all the time positive values which means that the automotive supply chain in UK during the period of analysis has a social responsibility behavior investing in improving the working conditions by decreasing the "Number of lost-time incidents" and improving the "Number of training days per employee" and the "Total number of employee". 


\section{CONCLUSIONS}

The proposed framework to assess the sustainability index is simple and easily understood by professionals, representing an important management tool. It serves an important role in supporting decision making for all three elements of the triple bottom line. Companies are often less concerned with the social and environmental dimensions of sustainability as they tend to think of corporate social responsibility in generic ways. The existing approaches to social and environmental initiatives are fragmented and disconnected from strategy which can lead to conflicting social, environmental, and economic objectives. Instead organizations must explicitly link environmental, social, and economic goals within a broader strategic perspective to ensure that environmental and social initiatives are reflected in the triple bottom line. Using this framework helps supply chains to evaluate the impact of their strategies and management practices on their sustainability. The framework suggested in this paper offers managers a starting point for assessing their supply chain sustainability and, at the same time, provides an opportunity to improve their social, economic and environmental behavior.

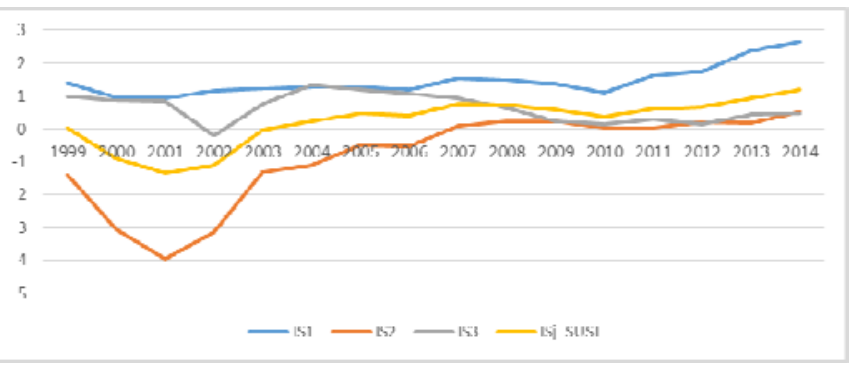

Legend: IS $\mathrm{I}_{1}$ - Economic dimension; IS2 - Environmental dimension; IS3 Social dimension.

FIGURE III. COMPARISON OF SUSTAINABILITY SUB- INDICES AND SUPPLY CHAIN SUSTAINABILITY INDEX

However, a variety of challenges face the user of this framework. One area of ambiguity relates to the selection of the indicators and the choice of weights for each of the sustainability dimension. The involvement of the most important stakeholders in the sector at this stage will determine the identification/representativeness of the framework. A second area where problems may arise relates to the data collection process for the sustainability indicators which are central to calculating the supply chain sustainability index.

\section{ACKNOWLEDGMENT}

This research is funded by Fundação para a Ciência e Tecnologia (UID/EMS/00667/2013) and FEDER/COMPETE (grant UID/ECO/04007/2013).

\section{REFERENCES}

[1] M. F. Salvado, S. G. Azevedo, J. C. O. Matias and L. M. Ferreira, "Proposal of a sustainability index for the automotive industry," in Sustainability, vol. 7, pp. 2113-2144, 2015.

[2] P. Ahi and C. Searcy, "A comparative literature analysis of definitions for green and sustainable supply chain management," in Journal of Cleaner Production, vol. 52, pp. 329-341, 2013.
[3] S. Seuring and M. Muller, "From a literature review to a conceptual framework for sustainable supply chain management," in Journal of Cleaner Production, vol. 16, pp. 1699-1710, 2008.

[4] S. Vachon and R. D. Klassen, "Extending green practices across the supply chain: The impact of upstream and downstream integration," in International Journal of Operations Production Management, vol. 26, pp. 795-821, 2006.

[5] C. Labuschagne, A. C. Brent, and R. P. G. van Erck, "Assessing the sustainability performances of industries," in Journal of Cleaner Production, vol. 13, pp. 373-385, 2005.

[6] R. Singh, H. Murty, S. Gupta and A. Dikshit, "An overview of sustainability assessment methodologies," in Ecological Indicators, vol. 9, pp. 189-212, 2009.

[7] V. Veleva and M. Ellenbecker, "Indicators of sustainable production: Framework and methodology," in Journal of Cleaner Production, vol. 9 pp. 519-549, 2001.

[8] I. Erol, S. Sencer, and R. Sari, "A new fuzzy multi-criteria framework for measuring sustainability performance of a supply chain," in Ecological Economics, vol. 70, pp. 1088-1100, 2011.

[9] S. G. Azevedo, K. Govindan, H. Carvalho and V. Cruz-Machado, "An integrated model to assess the leanness and agility of the automotive industry," in Resources Conservation Recycling, vol. 66, pp. 85-94, 2012.

[10] S. G. Azevedo, K. Govindan, H. Carvalho and V. Cruz-Machado, "Ecosilient Index to assess the greenness and resilience of the upstream automotive supply chain," in Journal of Cleaner Production, vol. 56, pp. 131-146, 2013

[11] D. Krajnc and P. Glavič, "A model for integrated assessment of sustainable development," in Resources Conservation and Recycling, vol. 43, pp. 189-208, 2005.

[12] P. Zhou, B. W. Ang and D. Q. Zhou, "Weighting and aggregation in composite indicator construction: A multiplicative optimization approach," in Social Indicators Research, vol. 96, pp. 169-181, 2010.

[13] A. P. C. Chan, E. H. K. Yung, P. T. I Lam, C. M. Tam, and S. O. Cheung, "Application of Delphi method in selection of procurement systems for construction," in Construction Management \& Economics, vol. 19, pp. 699-718, 2001.

[14] K. P. Yoon, and C.-L. Hwang, "Multiple attribute decision making: An introduction," in Sage University Papers, 1995.

[15] M. A. Shafia, M. M. Mazdeh, M. Vahedi, and M. Pournader, "Applying fuzzy balanced scorecard for evaluating the CRM performance," in Industrial Management \& Data Systems, vol. 111, pp. 1105-1135, 2011 